\title{
Learning Processes towards Destination Development
}

\author{
Anette Oxenswärdh ${ }^{1, *}$, Camilla Saggiomo ${ }^{1}$, Aida Alonso $^{1}$, Iida Pyykkö ${ }^{1}$, Lena Rothe ${ }^{1}$, \\ Patrycja Metlewicz, and Elena Kropinova ${ }^{2}$ \\ ${ }^{1}$ Uppsala University - Campus Gotland Department of Engineering Sciences, SE-621, 67, Visby, \\ SWEDEN \\ ${ }^{2}$ The Immanuel Kant Baltic Federal University, 236041 Kaliningrad, Russia
}

\begin{abstract}
Sustainable development of tourist destinations is based on the key principles of sustainable development in general taking into consideration the characteristics of tourism as an activity, in particular. In the event that a tourist destination has an island location, this becomes an additional factor imposing even more stringent requirements for sustainable development due to even greater vulnerability of isolated ecological systems. At the same time, the human factor becomes decisive, because the development of a tourist destination depends on how the providers of tourism services comply with the principles of sustainable development. The purpose of our study is to identify the willingness to follow the principles of sustainable development of a tourist destinations among entrepreneurs providing tourism services, using innovative methods of problem-solving learning. During the study, the following methods were used: bibliographic, analytical, in-depth survey method, etc. The methodology implemented for this study was qualitative survey where students reflected on their learning processes. The results show the importance of university students cooperating with actors within tourist destination on both theoretical and practical issues of sustainability to develop the destination. This cooperation enables the most important learning outcomes for both parties on sustainability. Heterogeneity of the group, and methodology of Design Thinking increases the creativity in problem solving.
\end{abstract}

\section{Introduction}

The issues of sustainable development of tourist destinations within the island territories are the subject of many studies. The fragility and environmental, social and economic vulnerability inherent in these areas make it increasingly important to integrate multiple aspects of sustainability into decision-making processes related to the definition of plans and programs for investment in the tourism sector [1]. However, mainly these works are devoted to territories located in subtropical and tropical latitudes, and developed with the

\footnotetext{
* Corresponding author: ribnikoff@yandex.ru
} 
growing popularity of beach tourism. Therefore, the main problems highlighted in the research are connected precisely with mass tourism (overtourism), the consequence of which is the destruction of endemic flora and fauna [2]; destruction and pollution of the coastal environment [3]; problems with drinking water [4, 5]; destruction of coral reefs [6]; conflicts of natural resources [7]. Separate studies are devoted to the landscape diversity of island landscapes $[8,9]$. The islands of the Baltic region have received less attention in the scientific literature. A small number of works tell about their historical and cultural heritage [10].

Based on the results of studies of the state of the environment of island tourist destinations, most researchers come to the conclusion that planning for their sustainable development should be carried out with the involvement of the public and stakeholders in decision-making process [11].

The role of tourism enterprises in the sustainable development of the territory is beyond doubt. A number of studies confirm this fact. For example, in their work on the example of water consumption in the Bolear Islands, Deyà Tortella, B. \& Tirado proved that the awareness of the introduction of water saving systems on the initiative and directly in hotel enterprises can reduce by $13.6 \%$, while the existence of the Department of Environment, neither the recognition of the strictness of water legislation, nor the cost of water play a significant role [5].

We also share the positions of Eckert and Pechlaner, regarding the fact that the starting point of the strategic development of the product is the resource values of the territory and the key competencies associated with a particular tourist destination. We believe that the foundation for its sustainable development is the support of the principles of sustainable development by a wide range of stakeholders within the destination. After all, it is this approach that makes it possible to lay the foundation both for the development of innovative products and for specific development directions that are new for a given destination.

According to Eckert and Pechlaner, both the demand for different products or services and changes in socio-spatial behavior can affect the impact of tourism and, as a consequence, its perception in the destination [12]. Revealed expectations on the part of tourists made it possible to identify such new directions of development for the tour operators, such as gastronomy, the use of electric vehicles, a more efficient introduction of public transport on renewable energy resources, etc. A significant role is played by the tour. operators. And, in this case, the educational component of sustainable development matters.

Thus, the analysis of the sources on the research topic allows us to draw the following conclusions:

- when studying the features of the development of sustainable tourism in island territories, researchers analyze various points of environmental stress and levels of interaction between actors;

- regardless of the research topic and the methods used, the authors come to the conclusion that the sustainability of a tourist destination depends on the involvement of entrepreneurs in the planning and implementation of the principles of sustainability, involved in the creation and implementation of a tourism product.

In this context, the educational component, aimed at problem-oriented methods of studying destinations, is of particular relevance. Regarding motivation as one of the important issues, when we talk about the students' approach to sustainable development, in our didactic purposes we pay great attention to the formation of ecological attitudes, rational behavior, positive actions in relation to nature, combining all these aspects as a path to personal success [13].

Considering the fast-paced and rapidly changing globalized environment we live in; real-world education is needed that enables learners to translate their theoretical knowledge 
into practical and innovative solutions. Higher education has been widely recognised to equip students with knowledge and capabilities to build a sustainable future [14, p. 286]. Furthermore, according to Schamber and Mahoney [15, p. 104], group work can develop problem-solving, critical thinking and lifelong learning skills.

The purpose of our study is to identify the willingness to follow the principles of sustainable development of a tourist destination among entrepreneurs providing tourism services, using innovative methods of problem-solve learning. In our work we will focus on studying the impact of innovative teaching methods as an important element of sustainable development of tourist destinations, we will evaluate how through in-depth interviews there is mutual training of interviewers - Master students of the programme "Sustainable Destination Development" and interviewers - representatives of travel companies. This research was carried out on the example of Gotland Island - one of the most popular tourist destinations in the Baltic region.

A feature of Gotland is both its natural heritage and rich historical and cultural resources, including the city of Visby - a UNESCO site. One of the emerging characteristics has been the clear connection of natural and cultural elements as attraction factor to Gotland [16].

As noted in the review Gotland in Figures, "The northern part of the island is barren and rocky, while the southern part is greener, with deciduous forests and wooded meadows. Some of Gotland's most striking natural attractions include orchid fields, limestone wastelands, beaches and idyllic meadows. We also have raukar - exotic stone pillars shaped by the wind, wild Gotland ponies and vibrant small cultural landscapes with walled pastures and many sheep that keep the land open to graze. ". $8 \%$ of the territory belongs to specially protected areas, including $1.2 \%$ occupied by the national park. All this leads to a massive influx of tourists, whose number has increased over the past 10 years to 800 thousand per year. Most of them are tourists from Sweden (over 80\%). Tourists from Germany (about 30 thousand) and Norway (about 20 thousand) prevail among foreign tourists. In addition, Gotland is a holiday residence for the Swedes. Tourism is seen as one of the two most important industry areas for the future development of the island, the other being food industry [16, P.14].

\section{Educational programs in the field of sustainable development of tourist destinations}

Among the factors contributing to the sustainable development of tourist destinations, training of specialists for the tourism industry plays a special role. After all, it is their way of doing business that will determine how great the benefits from the point of view of nature management for the environment are and how much the negative impact is minimized. With the help of greening education received by specialists of any profession, it is possible to shape a new look of the destination. At the same time, it is necessary to introduce new educational programs that include an obligatory component of education for sustainable development, for example, as a joint Masters' program "Tourism Marketing for Sustainable Development", implemented at the Immanuel Kant Federal University in 20072010, or the current Masters' program at Uppsala University "Sustainable Destination Development". At the same time, an important role is played by the improvement of teaching methods, as well as taking into account the specifics of the destination, in our case, the island location of Gotland.

Education for Sustainable Development is recognized as an integral element of Sustainable Development Goal (SDG) 4 on quality education and a key enabler of all other SDGs. It is widely recognized that higher education can equip students with the knowledge and ability to build a more equitable and sustainable future. Historically, higher education 
has played an important role in transforming society by educating scientists, entrepreneurs, leaders and decision-makers [17, p. 3].

Innovation and problem-solving skills have been taught in higher education through the cohesive framework of Design Thinking (DT) [18, p. 3]. Considering the description of DT, by [19] Stanford et al. (2017) as "a philosophy, a mindset, a set of core principles, and a satchel full of tools", DT is applicable to a multitude of disciplines. As a team being in the centre of DT, the innovative process can facilitate team building [20]. With this in mind, the purpose of this article is to describe the learning processes that a group of master students experienced while designing a training programme for tourist entrepreneurs in sustainability, in order to develop the destination. These learning process has been facilitating the design of sustainability education for Bed and Breakfast (BnB) owners, which as a process, in turn, can be seen as a part of destination development.

\subsection{Design thinking for problem-solving}

DT characterizes the mental processes that practitioners use as they frame, explore and reframe problems to derive design solutions. Today, professional fields such as engineering, architecture and business are recognizing that DT can be more effective for solving the complex problems than systematic problem-solving processes [19;20]. Also increasing numbers of governments have been exploring the potential of DT in meeting national problems and challenges, e.g., Denmark [21, p. 287]. DT has been promoted even in university education by establishing programs that are focused on cultivating DT in the countries such as the Asia-Pacific region, China, South Korea, and India [22, pp. 55-59].

DT as an activity has been used in different disciplines since 1987, starting with industrial and graphic design as well as engineering and architecture [23, p. 285]. DT as a method and a model has lately spread into a big number of disciplines and it has a multi- or interdisciplinary character through problem-solving and demands of the ability to synthesize knowledge from a variety of sources [24, p. 223]. That is why the problemsolving process frequently involves planning and sketches but also creating and use of models and prototypes. These tools provide alternative paths to experiential learning and serve often as the basis for the accumulation of tacit knowledge. Consequently, they can help to discover new knowledge or modes of thought [25, pp. 32-58]. There have been some critics expressed on DT approaches, though. Lack of critical thinking during the process has been one major object for criticism lately by several researchers [23, p. 285; 26, p.147].

\subsection{Learning individually and in a group}

The concept of learning has been described through different scientific disciplines and perspectives throughout history. Two main streams in this research are individual and group learning [27, pp. 9-15]. In this study, the principal focus are theories that can bear relevance to the perspective on joint learning processes in higher education. Theories of individual learning are, though, crucial for understanding joint learning processes. In theories about learning that focus on the individual, the importance of concrete experience is often emphasised. One of the theories is Kolb's Experiential Learning Theory (ELT). The importance of experiences in forming learning has been initially acknowledged by Kolb [28, p. 205] who stated that an individual experiences a situation, analyses it and understands the meaning and value of the particular situation in his own perspective. The ELT is interesting from the perspective of learning for sustainability because it focuses explicitly on the relationship between cognition and action, rather than on the increase of an individual's stock of knowledge. Kolb's theory has thought limitations. The focus in the 
theory is on learning from and through (primarily) individual experience. The theory does not take into consideration the contextual aspect, i.e., how some learning is influenced by social settings. It also overlooks the role of values and interests that influence human action. In the pursuit of learning sustainability, it is important to take both these issues into consideration [29, p. 38]. Group learning is more complex and dynamic than a mere magnification of individual learning. The level of complexity increases tremendously in the change from a single individual to a large collection of diverse individuals. Issues of motivation and reward, for instance, which are an integral part of human learning, become doubly complicated within groups. Action learning is an approach pioneered by Revans [30, p. 3]. According to him, learning can be witnessed only through some form of noticeable change in behaviour. Change is essentially a process involving learning and action. Without learning there can be no action; without action, there can be no proof of learning. - The growth of action learning is attributable to the notion that participants best learn new behaviours and problem-solving skills through real-world issues [31-32]. In action learning, participants typically work in small groups where they meet regularly to solve the issues encountered by them. They analyse, develop solutions, choose the most appropriate one, and implement their recommendations. Action learning is primarily a way of managing change through a learning process. Learning consists of programmed instruction and questioning insight [33, p. 22]. Working in groups or teams is a key requirement for learning. The period of collaboration in learning at times can lead to confusion, differences of opinion, and conflicts [23, p. 114]. But interacting with diverse co-learners often creates a discontinuity [34, p. 347] which reveals hidden assumptions and help to gain a broader view of the whole learning process. To summarize the aspects of learning above, it can be stated that learning is valued in this study by incorporating both individual and group learning processes.

\section{Methodology}

The students that participated in the study were part of the Master programme 'Sustainable Destination Development' at Uppsala University Campus Gotland. In brief, the aim of the Master programme is that students learn to analyse the different dimensions of sustainability. By the interdisciplinary design of the programme, the students can choose from three different specializations such as 'Applied Heritage Politics', 'Sustainable Nature-based Destinations' or 'Entrepreneurship for Destination Development”.

It is also important to point out in this context that the participants of the group were truly heterogeneous, in terms of nationality as well as professional background. Considering their country of origin, the students came from Mexico, Brazil, Finland, Luxembourg, and Germany. Likewise, they hold undergraduate degrees ranging from Geography, International Business, Fashion, Marketing, to Publicity.

The research was conducted using a qualitative, deductive approach with an online survey methodology to analyse and discuss how the DT as a method for innovation has helped master students go through the process of learning and producing new knowledge; and sustain solution on how to plan and provide sustainable education for BnB owners. Primary data collection for this study took place between January 2020 and July 2020. The survey included questions over the students' learning processes.

The analysis of the responses follows the themes in students' reflections over the process and are interpreted based on the theoretical perspectives described in the theory section. After the one-month course, the five master students involved in this study wrote reflections on the process they went through with following points of departure: how the DT method was used with problem-solving and reflected on all stages (empathize, define, ideate and prototype); learning process and outcomes as an individual; learning process and 
outcomes as a group and the opinion as individuals on why the DT method is a good tool to solve sustainability issues.

During the learning process, the students worked corresponding to the cyclical process of the DT as a structure; empathizing with the target audience by understanding their needs, i.e. interviewing hosts of $\mathrm{BnB}$ facilities and gathering their data; defining and finding the root causes and issues to the problem; ideating and creating solutions that solve the project's problem by creating collaborative brainstorming; prototyping a solution that can be implemented in a small scale; testing the created prototype and if necessary finding new improvement opportunities. The chosen methodology of students reflecting on their problem-solving process enables a more creative and holistic perspective on how sustainable education can be implemented through an innovative group learning process. The study provides insight into the benefits and challenges of group work using DT. The results highlight the importance of interpersonal communication for the learning outcomes of the group. Ultimately the study recognizes that project-based learning increases the motivation of the group members and creates a sense of group affiliation. Based on that, the data collected by the researcher was analysed, by using categorization.

Research ethics was considered throughout the process of data collection and confidentiality has been maintained throughout the whole research. All respondents from the interviews have participated on a voluntary basis and everyone will remain anonymous throughout the entire article. The group of master students agreed on being part of the research and article prior to participating in the course and gave permission on their reflections to be analysed, observed, and examined for the purpose of the research. Furthermore, the development of the work during the analysis and discussions was visible and open to suggestions to everyone during the process and development of the research.

\section{Presentation and analysis of the results}

The purpose of this article was to describe the learning processes that a group of master students experience while designing a training programme in sustainability for tourism entrepreneurs in order to develop the destination. In the following sections student's learning experiences with a focus on the benefits and challenges of individual and group learning experiences are presented and analysed. It will also be discussed how DT as a method served to consolidate the team and how its effectiveness can be applied to solve sustainability issues. Lastly, it will be concluded how these findings are able to develop the destination.

\subsection{Individual learning processes - the benefits}

The results indicate that, working in a team allows its participants to develop a high level of self-awareness, as well as paving the way to new learning and skills development. Each member of the team will go through the stages of consolidating their own skills and abilities in each of the tasks the team will have to perform, as well they will identify their own limitations and areas of improvement and will determine how they can be complemented by the other members of the group.

"Our group was constituted by a good mixture of people that had organized and structured personalities and others that were the more creative type. I would say I fell somewhere in between"

This is clearly stated by the theory presented by [36, p. 169] Zimmerman (2008) that mentions "students engaging in group work are simultaneously developing their own skills of self-regulation in their learning by increasing their skills of metacognition, motivation 
and behaviour". This can be observed when one of the students describes the process of identification of their individual's strengths and what they could contribute to the project. This process of self-regulation was viewed as a challenge by the students in the beginning, but the contemplation and realization of their own abilities and their peers seemed to have helped the students develop an important process of familiarization with the team. The group experiences have helped them create an optimal environment to deal with wicked problems related to sustainability. The fact that the students knew each other beforehand may have played a role in skipping the first stages of social interactions, but the process of self-regulation in their learning was still shown as necessary to develop a rapport with each other.

Empathy was seen by the students as an instrument to reflect on personal abilities and limitations and most importantly to understand other members' competences and how together they could build a strong project framework for the destination development. In a destination various voices and diverging opinions exist. By learning to empathize with other stakeholders not only the destination development can improve but also important aspects of sustainability are considered.

Individual learning in this project presented itself as a varied process for all the team members, but in the end, each of them was able to successfully self-determine which assets could be beneficial for the work to be done as well as to be able to apply new knowledge and acquire new professional and personal aptitudes.

"I felt I was using my skills and knowledge from previous training in my professional, personal and academic life as well as learning new things".

Intrapersonal awareness came to play an essential part in the forming and consolidation of the team, as it was important for the students to have a personal expected learning outcome, which helped them navigate and take on the project with open-mindedness and willingness to learn. This in the end made capable individuals which in the end formed a capable team.

Another relevant theory to mention in the process of individual learning is ELT by Kolb $[28,29]$. He mentions the critical importance of personal experiences while forming learning, it is crucial to understand how people analyse and understand these situations to acquire knowledge. Each of the members of this group was able to develop their intrapersonal skills, form personal learning outcomes and gain new expertise from this project. Which shows that being able to participate actively as an individual, assess abilities and limitations and to self-reflect on the process, creates a fruitful environment for more efficient group work.

\subsection{Individual learning processes - the challenges}

While there are many beneficial aspects related to individual learning in group work, there are as well hindrances that each group might need to take into consideration when embarking in group work that involves innovative solutions for sustainability issues. When it comes to the challenges faced when working in a diverse team, the students reported that initially in the first phase of the group formation they went through a challenging process of understanding their own skills as individuals and as a group. In the qualitative data collected, such processes included discerning the individual's strengths and what they could contribute to the project, as well as how the strengths between themselves could complement each other. This was described by one of the members of the group as " $a$ journey of discovery and adaptation".

The task of understanding one's personal skills can also be a challenge and could cause conflicts in the team, this is due to the fact that certain members of the group will be compelled to take taxing roles in which they will have to focus more on mediating and 
solving possible conflicts, rather than focusing on the main task of the project. One of the students in this group mentioned in the reflection how she took the role of mediator, she acknowledged that it was hard working with people with different personalities from her own, however, she was able to keep in mind the main goal of the project and move to the next tasks when necessary.

Although group work is favourable for most of the people involved in it, as it brings self-awareness to each team member, one of the caveats that are relevant to denote is the possible miscommunication and asymmetry when dividing the work and task, less outspoken or less assertive team members can feel they are contributing less as their more vocal counterparts. One of the team members in this group stated this concern when she realized that there were more active people in the team, this made her internalize her own capabilities and she concluded that she could have done more for the project.

The challenges that were present in this team were clearly identified in the early stages of the work, and as with the benefits mentioned above, they went through a process of personal self-discovery and self-awareness. One student mentioned that the learning outcomes of this exercise came with "better understanding of my own interpersonal relationships". For the team, it was important to recognize possible challenges and caveats within each of them to be capable to work on them and then to build trust with the teammates during the project and in future endeavours.

\subsection{Group learning processes - the benefits}

The results show that working with a diverse group became a substantial source of learning, as the diversity in the team brought different capabilities that were used to see the bigger picture regarding their problem statement. These results can be linked with Schön's (1995) theory on cognition and action, where he states "theories-in-use that people from different professional and cultural backgrounds hold will influence the possibility for them to learn collectively."

"I had to work with people that prefer more free environments and prefer less structured analysis or things, at the beginning I would have thought this could have posed a great barrier in our group effort and dynamics, but I believe we took this as an opportunity to grow and find compromises and the solutions we were looking for."

When referring to clear factors to enhance learning in a group setting, it was mentioned by the students that heterogeneity was crucial for their experience, with emphasis giving to the contrasting personalities between them. The theory by Gurin et al. (2002) show that when working with diverse co-learners hidden assumptions can be revealed, which in the end helps gain a broader view of the whole learning process and can improve academic performance [35]. Diverse co-learners in the case of this study can be viewed as the diversity in individual psychological processes, more than diversity in terms of nationalities and professional backgrounds. That could open the possibility to use such psychological diversity as a point of departure in creating diversity within groups of students or stakeholders that might be considered homogeneous at first, consequently developing a better learning experience. Gurin et al. (2002) also add that working in a diverse group makes students more inclusive and democratic, which in this study is shown that such qualities can create synergy and symmetry in teams and assist them in positively challenging each other's views to move forward in the process of creating innovative solutions.

Through the process of learning about the main beneficiaries together as a group and focusing on "the problem behind the problem", the students realized the true complexity of the subject. An important finding in such a process was that in order to educate people on sustainability, there must be a shift on existing paradigms, and this can only be done 
through inspiration to change notions and attitudes. "Inspire instead of educate" became the means to create sustainable development for all parties involved in the project. This led the group to create a prototype solution that was people-oriented and focused on real needs, pains, and gains in contrast with the original proposal to provide a methodical sustainability curriculum for BnB owners on the island of Gotland.

\subsection{Group learning processes - the challenges}

A challenging task encountered by the students and found in their reflections, came when they entered the brainstorming phase, as different assumptions of the project and possible solutions were interpreted differently by the distinctive personalities of each group member, as they clearly mentioned before, the creative team members had ease when navigating more abstract concepts, while the pragmatic members focused more on the task at hand and immediate deliverables. This distinction led the team to a motivation to learn and overcome challenges of miscommunication and misinterpretation. Although this process took time and energy it was eloquently concluded by one of the students that "we always managed to consider everyone's ideas and contributions" and "at the end we found a solution that took part of both imaginative and realistic approaches".

The process of developing a common understanding as a group regarding a subject or task could be considered as an important requirement to work in teams that can successfully learn and develop new behaviours. The common understanding can be developed in different ways through collective learning, and it must be based on social activities, as defended by [27] Granberg and Ohlsson (2016). The many activities undertaken by the students throughout the project to understand and learn together about the main beneficiary, stakeholders' needs and education for sustainability could show the effective learning process that collaborative learning approach can provide to students, even though it can take time and effort. It can also be added that the importance of jointly problematizing and reflecting on the experience in collective learning defended by Wilhelmson (1998) can be maximized in a heterogeneous group, as in the results show that it allowed them to understand the main beneficiary and stakeholders from different angles [37].

The process of developing a common understanding in this instance gave the group the basis to jointly redefine the original problem statement, adjust preconceived notions and initial strategies and finally arrive at a satisfactory answer to the problem in hand. Interconnectedness can be observed in collaborative learning and collective learning when the group is working together to make sense of tasks and information to solve problems. The process of developing a common understanding as exemplified through the student's experiences led them to take different courses of action and approach to the problem that in Action Learning can be interpreted as participants learning new behaviours and problemsolving skills through real-world issues stated by Toegel (2002) [32] and added by Pedler (2016) [30], learning can be witnessed only through some form of noticeable change in behaviour.

\section{Discussion: the interconnectedness of the learning journey and sustainable destination development}

As described in the introduction part, planning and management for sustainable destination development is complex and multifaceted. Historical tourism in Gotland is seen as an integral part of the island's tourism complex, and not as a separate industry. Heritage elements are essential to Gotland's universal image as a 'magical island', a place different from the rest of Sweden. " [16]. However, despite its rich heritage and attractiveness, 
Gotland has a short season and needs to attract tourist during more times than in the summer [38, P.601]. This is the main problem for both government officials and representatives of the tourism industry. Destination conditions influence the reasons why tourism manufacturers seek to work with sustainable tourism. ustainable tourism is used by the tourist producers as a strategic marketing tool but in different ways depending on the destination.. It is no longer a difference between many services; instead the tourist producers must work with sustainable tourism as a part of the final value that the tourist is buying. [38, P.602].

Thus, destination management requires not only a deep understanding of multiple disciplines, but also skills such as systems thinking or anticipatory competences. Learning processes on an individual as well as group level can be observed separately in the instances above, but their interconnectedness is noticeable at all moments in the learning experiences, reported by the students. The self-regulation process that the students went through, was only triggered by the wish to familiarize, and fit in the group. It can also be added that the motivation to work in a group comes from the personal values and interests that are aligned with team members' and the project.

This personal experience of learning can be noticed when the group highlights how its heterogeneity helped analyse the issue from different points of view, meaning that if the individual understanding of members of the groups had not been expressed, there would not be the opportunity to come to a common understanding. For instance, as this group of master students developed a sustainability education for $\mathrm{BnBs}$, the stakeholders in a destination are required to diversify the offer in a destination through cooperation as well as learning from each other. The results indicate that the students have developed these capacities during their learning process. In line with previous studies [39; 40] for a destination to flourish a network of stakeholders need to go through similar group learning processes.

\section{Design thinking as a framework for problem-solving}

DT as a problem-solving tool in this study provided freedom for the students to go back and forth in the process whenever a new piece of knowledge was acquired, which put the focus on experimentation and creativity by helping the users frame, explore and re-frame problems to derive design solutions, instead of having a systematic process [31] to find a solution to the problem originally presented. Although still being a process where users are required to work through all the stages, the cyclical and overlapping nature of DT provides a framework where users could test proposed ideas, assess the results, and reconvene if necessary, by restarting the process, which is not possible with systematic problem-solving processes.

The empathetic approach DT put into the research phase of the process seems to propel its users to broaden the possibilities within the research subjects related to the problem stated creating a multi- or interdisciplinary character through problem-solving and helps clarify the context where it is inserted. This kind of approach to problem-solving in the case of the students has been effective in helping them acquire and synthesize knowledge from a variety of sources as Kurokawa mentioned and adjust preconceived notions regarding the problem and its beneficiaries. But developing empathy as a group or individual, through the DT process towards the beneficiaries could be biased, as empathy can be produced based on personal experiences and views of the world. Another point is that developing empathy without involving the problem-owner could impose the challenge of creating conflicting views regarding the proposed solution. So, while DT can provide alternative paths for experiential learning and serve often as the basis for the accumulation of tacit knowledge defended by Brown (2009), the solutions developed by using the methodology could be 
very influenced by personal views and as stated by Dunne (2018), could create problems of ethical art, where users can manipulate the choices available.

Finally, although DT was acknowledged by the students as a powerful tool to solve a particular sustainability issue identified by BnB owners on the island of Gotland; it has yet to be seen how this tool could serve as a mechanism for problem-solving in a larger scale, with a more varied number of stakeholders with conflicting values and expected outcomes, as it was mentioned by Kimbell (2011) and Loewe (2019) one of the major criticism of the DT methodology is the possible lack of critical thinking; this is due to the fact that when solutions are presented participants will be biased towards to those that are more aligned to a certain expected outcome or are presented as more innovative, rather than to those that might seem simpler or are presented as less innovative. In the end, this could cause oversights and/or possible errors, however, more research will need to be performed in the future to decide whether DT is an efficient strategy to solve wicked problems.

\section{Conclusions}

Thus, a comparative description in the work of the learning processes that a group of master students experienced in developing a training program for entrepreneurs working in tourism and hospitality sphere in the field of sustainable development in order to develop a destination showed that the Design-Thinking methodology is the most effective and should be included into a sustainable education program aimed at Bed \& Breakfast service providers on Gotland [42]. After a month of collaborative problem-solving and experiences of individual and group learning, the team was able to conclude the project with an innovative solution that offered a holistic approach in which the social, environmental, and economic aspects of sustainability were at the forefront of priorities. As stated, the team focused on education through inspiration while at the same time suiting the needs of the project and stakeholders involved. However, building this kind of rapport might not be possible in all scenarios, group work will come differently for everyone involved in it.

All the aspects made this group of students come to a successful and positive outcome. It can be summarized that this study served to express the reflections that the students went through while working as a group and to internalize in their learning journey towards sustainable destination development. Following aspects of students' group learning can be transformed in describing the learning process for the $\mathrm{BnB}$ providers in their future course of sustainable destination development.

1. Individual learning comes from the ability to self-regulate and analyse one personal's abilities and deficiencies and how it can be complemented by the other team members.

2. A successful outcome might come from being able to be familiar with other team members on a personal level, as well as to share values and interests. It is important that a new team has the time to socialize before working together as this will be beneficial for the result.

3. Heterogeneity can be favourable for group work, as it allows people to become more inclusive. However, each group should be aware of how heterogeneous it is to be prepared for possible complications.

4. DT proved to be a valuable methodology for the learning outcomes of this team, as it allowed the students to empathize with each other and with the project stakeholders. It also opened the way to a free way of thinking in which creativity and innovation are encouraged.

5. Although DT proved to be efficient in the classroom, it is necessary to perform deeper research in its ability to solve more complex issues (wicked problems). The 
stakeholders could apply this methodology in their professional lives and analyse its effectiveness.

Finally, it is important to denote that generalizations cannot be made about each groupwork and scenarios; learning processes and outcomes are different in each group and the tools that can work for one are not guaranteed to work for all, nonetheless it is important to distinguish that most teams pass through the same stages of group work and learning from the ordeals of some can help improve the experiences and results of others. Lastly, it is relevant to include that in the changing atmosphere of sustainability studies and education as well as destination development, the ability to efficiently solve problems, work in heterogeneous teams, shift strategies and adapt to complex scenarios comes as a great asset to destination managers interested in inquiring deeper into the subject of sustainable destination development.

\section{References}

1. A. Nesticò, G. Maselli, J. of Cleaner Production, 248 (2020)

2. Y. E. Choi, K. Song, M. Kim, J. Lee, Sustainability, 9 (2017)

3. D. Karnauskaitè, G. Schernewski, J. Schumacher, et al., J. Coast Conserv, 22 (2018)

4. J.-H. Yu, H.-H. Lin, Y.-C. Lo, K.-C. Tseng, C.-H. Hsu, Water, 13 (2021)

5. T. B. Deyà, D. Tirado, J. of environmental management, 92(10) (2011)

6. J. A. Lara-Pulido, Á. Mojica, A. Bruner, A. Guevara-Sanginés, C. Simon, F. VásquezLavin, C. González-Baca, M. J. Infanzón, Sustainability, 13 (2021)

7. V. Duvat, Beach quality assessment as a tool for promoting sustainability in tourist islands: the case study of Oléron Island, France (2010)

8. A. Chen, Y. Ng, E. Zhang, M. Tian, Island Tourism Landscape (2020)

9. D. Chylińska, Geoheritage, 11 (2019)

10. E. M. Poort, U. Persson-Fischier, H. Martinsson-Wallin, E. E. Donaldson, M. Schaub, Sustainability, 13 (2021)

11. B. S. Tselentis, D. G. Prokopiou, E. Gyalirakis, D. Bouga, Tourism carrying capacity assessment and environment: the case of Crete (2011)

12. C. Eckert, H. Pechlaner, Sustainability, 11(13) (2019)

13. E. Krasnov, E. Kropinova, The Combined Effects of Education and Research on Sustainable Development in the Immanuel Kant Baltic Federal University (Russia, Kaliningrad), 2 (2017)

14. R. D. Lange, B. Marx, A.V. der Watt, J. of Economic and Financial Sciences, 6(2) (2013)

15. J. Schamber, S. Mahoney, The J. of General Education, 55(2) (2006)

16. M. K. Schaub, Natural and Cultural Heritage in Tourism on Gotland. Heritage Tourism Characteristics and the Relation of Natural and Cultural Heritage (2020)

17. J. Bowerman, Int. J. of Health Care Quality Assurance Incorporating Leadership in Health Service, 16(4) (2003)

18. W. Brenner, F. Uebernickel, T. Abrell, Design Thinking for Innovation (2016)

19. J. Stanford, E. T. Siminoff, M. O’Neill, J. Mailhot, What is design thinking? O’Reilly Media (2017)

20. T. Lembcke, A. B. Brendel, L. M. Kolbe, HMD 56, 2019

21. L. Kimbell, Design and Culture, 3 (2011) 
22. T. Kurokawa, Science \& Technology Trends Quarterly Review, 46 (2013)

23. L. Kimbell, Design and Culture, 3(3) (2011)

24. N. Cross, Designerly ways of knowing (2007)

25. T. Brown, Change by design: How design thinking transforms organizations and inspires innovation (2009)

26. S. Loewe, Towards a Critical Design Thinking: Propositions to Rewrite the Design Thinking Process (2019)

27. O. Granberg, J. Ohlsson, Collective learning in working life, 9

28. D. A. Kolb, Individual learning styles and the learning process (1971)

29. D. A. Kolb, Experiential learning: Experience as the source of learning and development (1984)

30. M. Pedler, R. Revans, The Palgrave Handbook of Organizational Change Thinkers (2016)

31. A. Buhl, M. Schmidt-Keilich, V. Muster, S. Blazejewski, U. Schrader, C. Harrach, M. Schäfer, E. Süßbauer, J. of Cleaner Production, 231 (2019)

32. J. Conger, G. Toegel, J. of Change Management, 3(4) (2002)

33. M. Pedler, R. Revans, The Palgrave Handbook of Organizational Change Thinkers, 22 (2016)

34. E. M. Rogers, Diffusion of Innovations (1995)

35. P. Gurin, E. L. Dey, S. Hurtado, G. Gurin, Harvard Educational Review, 72(3) (2002)

36. B. J. Zimmerman, American Educational Research J., 45 (2008)

37. L.Wilhelmson, Learning dialogue. Conversation patterns, change of perspective and learning in group conversations, (1998)

38. A. Sörensson, Sustainable tourism at mass tourist destinations: best practice from tourist producers in Europe (2010)

39. E. V. der Zee, D. Vanneste, Tourism Management Perspectives, 15 (2015)

40. M. Valeri, R. Baggio, Int. J. of Organizational Analysis (2020)

41. D. Dunne, J. of organization design, 7(1) (2018)

42. A. Oxenswärdh, Universities and Sustainable Communities: Meeting the Goals of the Agenda 2030 (2020) 